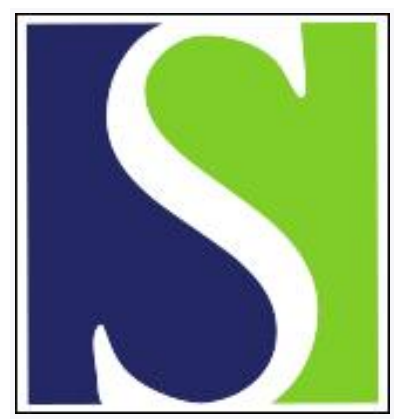

Scand J Work Environ Health 2008;34(1):23-32

https://doi.org/10.5271/sjweh.1195

Issue date: 29 Feb 2008

Influence of sleep on symptom improvement and return to work in clinical burnout

by Sonnenschein M, Sorbi MJ, Verbraak MJPM, Schaufeli WB, Maas CJM, van Doornen LJP

Affiliation: Utrecht University, Faculty of Social Sciences, Department of Clinical and Health Psychology, PO Box 80140, NL-3508 TC Utrecht, Utrecht, Netherlands. miekesonnenschein@ichthusgroep.nl

Refers to the following texts of the Journal: 2006;32(1):67-74 2006;32(2):121-131 2003;29(6):478-479

The following article refers to this text: 2010;36(6):515-516

Key terms: burnout; clinical burnout; intervention; return to work; sickness absence; sleep; symptom; symptom improvement; work resumption

This article in PubMed: www.ncbi.nlm.nih.gov/pubmed/18427695

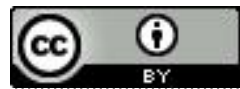




\title{
Influence of sleep on symptom improvement and return to work in clinical burnout
}

\author{
by Mieke Sonnenschein, PhD, ${ }^{1}$ Marjolijn J Sorbi, PhD, ${ }^{1}$ Marc JPM Verbraak, PhD, ${ }^{2}$ Wilmar B Schaufeli, \\ PhD, ${ }^{1}$ Cora JM Maas, PhD, ${ }^{1}$ Lorenz JP van Doornen, PhD ${ }^{1}$
}

Sonnenschein M, Sorbi MJ, Verbraak MJPM, Schaufeli WB, Maas CJM, van Doornen LJP. Influence of sleep on symptom improvement and return to work in clinical burnout. Scand J Work Environ Health. 2008;34(1):23-32.

\begin{abstract}
Objectives The current study examined the extent to which symptom improvement and full return to work occurs among clinically burnt-out employees and what the influence of concurring sleep problems is with respect to health recovery.

Methods Fifty-nine burnt-out employees on extended sick leave assessed their symptoms for 2 weeks using an electronic diary. After 6 months, the measurements were repeated. Symptom levels were compared with those of a healthy reference group that was assessed only once.

Results After 6 months, all burnout symptoms had decreased significantly, and full return to work was achieved by $37 \%$ of the burnt-out individuals. The symptom levels at 6 months of follow-up among those who had fully returned to work were similar to healthy levels and significantly lower than the levels of those still on sick leave. The persons who benefited poorly from sleep at baseline had higher exhaustion levels at follow-up than those who benefited from sleep. Trouble falling asleep and less refreshing sleep at baseline hampered eventual full work resumption.

Conclusions The results show that a significant number of clinically burnt-out employees is able to recover in a 6-month period and that sleep plays an important role both in symptom improvement and in return to work.
\end{abstract}

Key terms intervention; sickness absence; symptom; work resumption.

Occupational physicians are often faced with employees on sick leave due to work-related problems like burnout. Burnout is a serious syndrome that is characterized by severe exhaustion, a cynical attitude towards work, and low professional efficacy (1). Research suggests that the syndrome is resistant to spontaneous recovery, and studies are being undertaken to explain the persistence of burnout (2). In subclinical burnout samples, burnout levels have been shown to be stable over periods of up to 8 years $(3,4)$. Does this finding imply that employees who end up on sick leave due to burnout symptoms (clinical burnout) should not expect to recover? Studies on the stability of the burnout syndrome in clinical samples are still scarce, as are studies on the responsiveness of burnout to treatment (5).

\section{Recovery from clinical burnout}

Symptom improvement. Currently, only one study has compared a no-treatment condition to two intervention conditions among self-employed people on sick leave due to "work-related adjustment disorders" (6). The latter diagnosis covers the whole continuum of mild to severe burnout complaints (7). The treatment conditions consist of cognitive behavioral therapy $(\mathrm{N}=30)$ conducted by psychologists according to a standardized protocol (8) and activating intervention $(\mathrm{N}=28)$, based on cognitive behavioral therapy but conducted by labor experts and primarily focused on graded activity and workplace intervention. While cognitive behavioral therapy is symptom-contingent with return to work, depending on the degree of symptom improvement, activating intervention is time-contingent in stimulating return to work independently of symptom severity. Cognitive behavioral therapy and activating intervention did not promote symptom improvement and rendered results similar to the no-treatment condition $(\mathrm{N}=28)$. Without treatment, the exhaustion levels decreased significantly within the first 4 months after sick leave and further improved in the following 6 months. However,

1 Department of Clinical and Health Psychology, Utrecht University, Utrecht, Netherlands.

2 HSK Group, Arnhem, Netherlands.

Correspondence to: Dr M Sonnenschein, Utrecht University, Faculty of Social Sciences, Department of Clinical and Health Psychology, PO Box 80140, NL-3508 TC Utrecht, Utrecht, Netherlands. [E-mail: miekesonnenschein@ichthusgroep.nl] 
after these 10 months, the exhaustion levels remained above the clinical cutoff score for burnout, as assessed with the Maslach Burnout Inventory (9) [ie, >2.20 (10)]. In parallel, in another study, those with clinical burnout $(\mathrm{N}=51)$ who received cognitive behavioral therapy according to the same protocol (8) recovered from exhaustion (Maslach Burnout Inventory) in 8.5 months of treatment (11). The exhaustion levels remained elevated when compared with those of healthy normal groups, however, and stabilized in the next 6 months after cognitive behavioral therapy without a further decrease (11). The group in cognitive behavioral therapy was not compared with a no-treatment control group. Both studies showed comparable results for co-occurring depressed mood, anxiety, and sleep problems $(6,11)$. In summary, limited, but consistent evidence suggests that exhaustion decreases within approximately 10 months after sick leave but stabilizes thereafter at a level that remains elevated. Currently, neither cognitive behavioral therapy nor time-contingent activating intervention appears to promote symptom improvement.

Return to work. In addition to symptom improvement, return to work is a second important indicator of recovery from clinical burnout. The aforementioned studies are again consistent in that $50 \%$ of the participants had fully returned to work with or without treatment, either 11 months after sick leave (6) or 8.5 months after the onset of cognitive behavioral therapy, which is exclusive of the time between the onset of sick leave and that of cognitive behavioral therapy (11). However, activating intervention significantly advanced full return to work by $50 \%$ despite the lack of symptom improvement within only 4 months after sick leave. Thus activating intervention induced this result 7 months sooner than either cognitive behavioral therapy or no treatment (6). The superiority of activating intervention in promoting full return to work was confirmed in another study that yielded $78 \%$ full return to work in a group with workrelated adjustment disorder after 3 months, compared with $63 \%$ when "care as usual" was provided by occupational physicians (12). In summary, full return to work emerged as a slow process in clinical burnout, which can be speeded up by time-contingent activation, but which seems insensitive to the best available cognitive behavioral therapy.

\section{Role of sleep}

Sleep problems are reported both in the early (13-17) and end stages (18-20) of the burnout process, as assessed subjectively (19) and objectively $(16,20)$. Trouble falling asleep and nonrefreshing sleep are reported in particular $(15,16,19)$. Data on the same and following day from our current project have demonstrated that clinically burnt-out persons recover poorly through sleep (19). Evidently, sleep problems and poor replenishment of energy through sleep may hinder recovery from severe exhaustion in clinical burnout in the long run. As far as we know, no empirical evidence is available on this matter. We do know, however, that sleep problems and poor recovery appear to affect burnt-out individuals independently of depressed mood $(16,19)$, and regardless of comorbid major depression $(19,20)$. This situation suggests that sleep problems are an independent concurring symptom in burnout, despite the strong relationship between burnout and depression (21). In addition, sleep problems are related to long-term sick leave and work disability. In two large-scale epidemiologic studies, sleep problems predicted work disability, even after adjustment for psychiatric and physical morbidity and health-related behavior $(22,23)$. Consequently sleep problems appear to be an independent complicating factor in both symptom improvement and return to work in clinical burnout.

\section{Hypotheses}

The aim of our study was to examine the extent to which recovery from clinical burnout occurs. Twice (ie, at the beginning of treatment and after 6 months) we assessed a sample that had received "psychological treatment as usual". An electronic diary was employed to assess the severity of the burnout symptoms in daily life and to compare symptom improvement to the levels of healthy persons. Return to work was examined as a hard endpoint second indicator of improvement. In addition, we specifically examined the extent to which symptom improvement and return to work were hindered by sleep problems. We tested the following hypotheses: (i) within 6 months burnout symptoms will have improved in clinically burnt-out individuals to a still elevated level when they are compared with a healthy reference group; (ii) the greater part of the clinical burnout sample will not have fully resumed work after 6 months of psychological treatment if treatment is not directed towards activation; and (iii) symptom improvement and work resumption are hampered by sleep quality, more specifically, poor recovery through sleep at baseline impedes exhaustion improvement and sleep problems at baseline impede return to work in clinical burnout.

\section{Study population and methods}

\section{Study population}

Burnt-out employees were recruited from August 2004 until April 2005 from new enrollments at Dutch centers of expertise in burnout treatment and through the 
Internet. Internet recruitment was carried out by linking five national websites on burnout and stress to the research information on the university intranet. The selection process is depicted in figure 1. The following inclusion criteria were applied: (i) severe burnout complaints according to validated cutoff points from the Dutch Maslach Burnout Inventory-General Survey (MBI-GS) (exhaustion $\geq 2.20$ and either cynicism $\geq 2.00$ or personal accomplishment $\leq 3.67)(9,10)$ and the Checklist Individual Strength ( $\geq 76)$ (24); (ii) extended absence and enrollment in professional treatment due to burnout symptoms; and (iii) fulfillment of the criteria for work-related neurasthenia according to the International Classification of Diseases, 10th revision (25), the proposed psychiatric equivalent of clinical burnout (5). Patients were excluded when (i) suffering from primary psychiatric disorders (while allowing secondary psychiatric disorders), as assessed by a semistructured clinical interview (26) and the Symptom Checklist-90-R (SCL-90) [general severity index <214 (ie, above the mean score) plus one standard deviation of psychiatric outpatients] (27), (ii) using antidepressants or anxiolytics, or (iii) if pregnant. Healthy controls were recruited from April 2004 until March 2005 from the community through newspaper advertisements and personal contacts. They were matched with the burnout group for age, gender, and educational level. Healthy controls were excluded when they experienced burnout complaints (MBI-GS, CIS) or psychiatric complaints (SCL-90) or if pregnant. The characteristics of the participants are shown in table 1.

Potential participants were sent an information brochure and a screening questionnaire (including the MBI-GS, CIS, and SCL-90). When inclusion criteria on the screening questionnaire were met, a clinical interview was conducted at home or at the research center. The use of the electronic diary was explained during 1 hour of instruction at home, and the informed-consent form was signed. Technical backing was provided for the 2-week period of diary assessment. At the 6-month follow-up [mean 6.3 (SD 1.0) months], the procedure was repeated in the clinical burnout group, but not in the healthy reference group. After completing the study, the burnout participants were offered a remuneration of EUR 45, and the control participants received a remuneration of EUR 25. The study was approved by the Medical Ethics Review Committee of the Utrecht University Medical Centre.

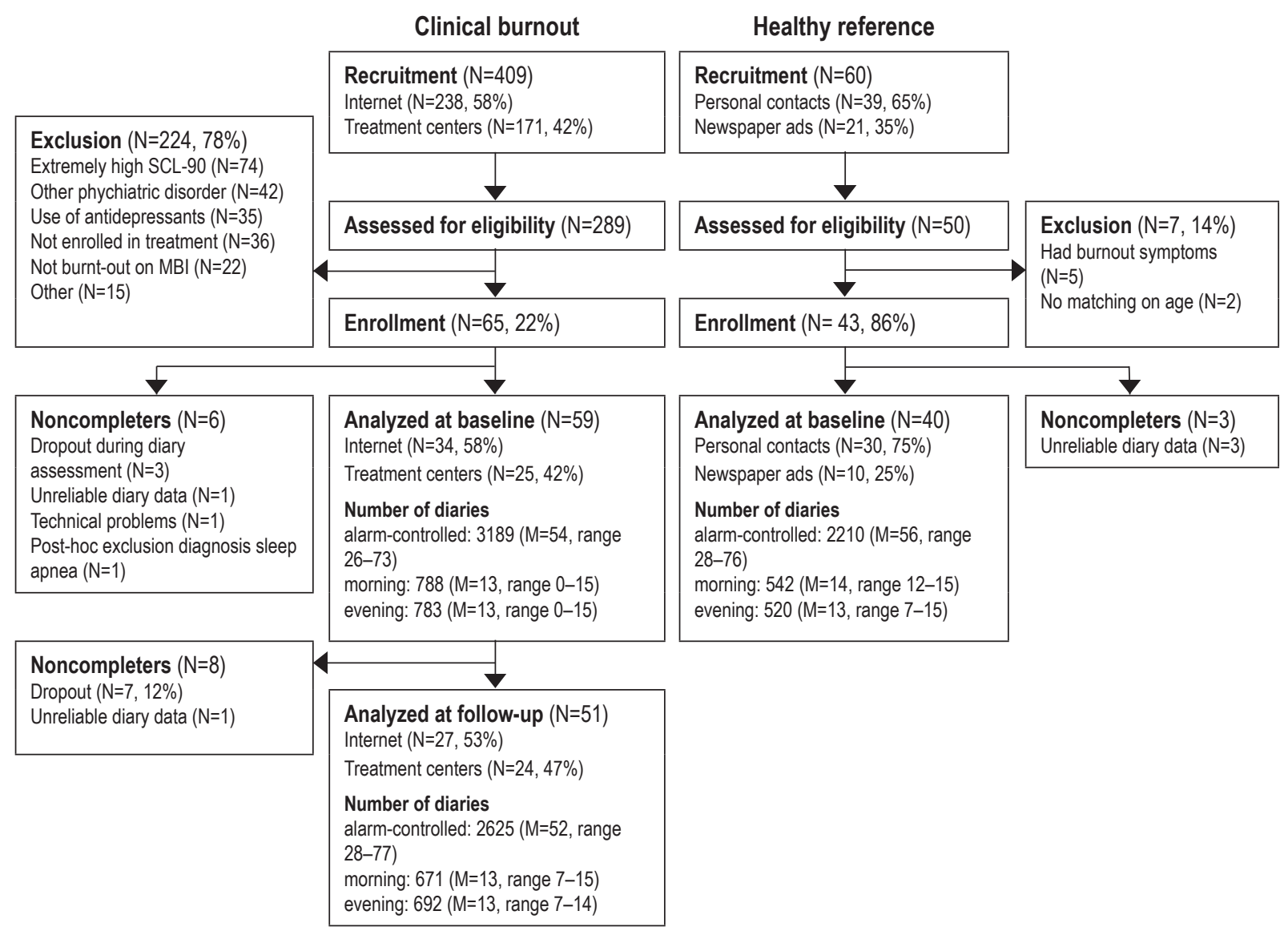

Figure 1. Participant selection. $(\mathrm{MBI}=$ Maslach Burnout Inventory, $\mathrm{SCL}-90=$ Symptom Checklist-90- $\mathrm{R}, \mathrm{M}=$ mean, ads = advertisements) 
Table 1. Baseline characteristics of the participants. [scale range of the subscales of the Maslach Burnout Inventory-General Survey $(\mathrm{MBI}-\mathrm{GS})=0-6$, scale range of the Checklist Individual Strength $(\mathrm{CIS})=20-140$, subscales of the Symptom Checklist-90-R (SCL-90) $=90-450]$

\begin{tabular}{|c|c|c|c|c|c|c|c|c|c|}
\hline \multirow[t]{2}{*}{ Variable } & \multicolumn{4}{|c|}{ Clinical burnout group (N=59) } & \multicolumn{4}{|c|}{ Healthy reference group $(\mathrm{N}=40)$} & \multirow[t]{2}{*}{ P-value } \\
\hline & $\mathrm{N}$ & $\%$ & Mean & $\mathrm{SD}$ & $\mathrm{N}$ & $\%$ & Mean & SD & \\
\hline \multicolumn{10}{|l|}{ Inclusion and exclusion criteria } \\
\hline Exhaustion (MBI-GS) & . & . & 4.74 & 0.99 & . & . & 1.19 & 0.54 & $<0.001$ \\
\hline Cynicism (MBI-GS) & $\cdot$ & . & 3.52 & 1.35 & . & . & 1.15 & 0.78 & $<0.001$ \\
\hline Personal accomplishment (MBI-GS) & - & . & 3.58 & 1.31 & . & - & 4.77 & 0.71 & $<0.001$ \\
\hline General fatigue (CIS) & . & . & 106.1 & 14.8 & . & . & 41.0 & 12.9 & $<0.001$ \\
\hline Psychopathology (SCL-90) & . & . & 181.0 & 30.7 & . & . & 104.1 & 11.0 & $<0.001$ \\
\hline \multicolumn{10}{|l|}{ Demographic variables } \\
\hline Age (years) & $\cdot$ & . & 42.9 & 8.82 & . & . & 41.8 & 9.98 & NS \\
\hline Gender ratio ( $\%$ male) & 26 & 44.1 & $\cdot$ & $\cdot$ & 14 & 35.0 & $\cdot$ & $\cdot$ & NS \\
\hline Education ( $\%$ college or university) & 34 & 57.6 & . & $\cdot$ & 26 & 65.0 & $\cdot$ & $\cdot$ & NS \\
\hline \multicolumn{10}{|l|}{ Complaints and sick leave } \\
\hline \multicolumn{10}{|l|}{ Sick leave } \\
\hline Full return to work & 31 & 52.5 & - & $\cdot$ & . & . & - & . & . \\
\hline Partial return to work & 28 & 47.5 & . & . & . & . & - & . & - \\
\hline Duration of sick leave (weeks) & 15.8 & 14.3 & . & $\cdot$ & . & . & $\cdot$ & . & - \\
\hline \multicolumn{10}{|l|}{ Comorbid psychiatric disorder } \\
\hline None & 38 & 64.4 & . & . & . & . & . & . & . \\
\hline Mood disorder & 8 & 13.6 & . & . & . & . & . & . & . \\
\hline Anxiety disorder & 6 & 10.2 & . & $\cdot$ & . & . & $\cdot$ & . & - \\
\hline Mood and anxiety disorder & 3 & 5.1 & . & $\cdot$ & . & . & . & . & - \\
\hline Mood and somatization disorder & 1 & 1.7 & . & . & . & . & . & . & - \\
\hline Other & 3 & 5.1 & . & . & . & . & . & . & . \\
\hline
\end{tabular}

\section{Methods}

At baseline the participants provided information on demographics, sickness absence, work resumption, and work adjustments in a general questionnaire. Symptom improvement was assessed through the monitoring of the electronic diary according to the standards of the Experience Sampling Method (28). The electronic diary was programmed into a PalmOne handheld computer using Pendragon software (29) and a separate program that generated randomized alarms (30). During 14 consecutive days, the participants kept the electronic diary every day; they assessed exhaustion, fatigue and sleep quality after waking up (morning diary), exhaustion and fatigue before going to bed (evening diary), and exhaustion, fatigue and depressed mood at an average of five random time points per day when prompted by an alarm (alarm-controlled diary). For the burnout group, compliance to the alarm-controlled diary was high both at baseline (83\%) and at follow-up (79\%), and it was comparable to that of the control group (80\%). Compliance to the morning and evening diaries was very high in both groups and in both assessment periods (range 93-98\%). The method was accepted well by the clinical burnout participants at both time points, as it also was by the healthy participants. No reactivity effects were detected (ie, changes in ratings of symptoms over time due to the method of diary keeping itself). The electronic diary method that we used has been described in more detail elsewhere (31).

The variables under study were measured with singular diary items, according to the premises of the Experience Sampling Method (ie, items were to measure states instead of constructs and mimic an internal dialogue) and thus needed to be short and easy to comprehend (32). Exhaustion was defined as a severe and stable form of fatigue that is no longer responsive to normal periods of rest and emerges only when fatigue becomes chronic (33-35). Exhaustion was measured by the statement "Right now I feel exhausted". Recovery through sleep was calculated as the difference between fatigue intensity at bedtime and at waking up the following morning. Fatigue was defined as the healthy expression of a lack of energy and was measured by the statement "Right now I am tired", which is, in spoken language, the common expression of fatigue of any kind (36). We assessed two subcategories of the fourth edition of the Diagnostic and Statistical Manual of Mental Disorders (DSM-IV), sleep problems (37) that are disturbed in clinical burnout (19) [ie, trouble falling asleep ("Tonight I had trouble falling asleep") and refreshing sleep ("Right now I feel refreshed")]. The item for depressed mood was "Right now I feel depressed", and it was based on one of the DSM-IV criteria for depressed mood in a major depressive disorder (37). Responses were given on a 7-point scale, anchored as $1=$ not at all and $7=$ very much. 


\section{Treatment characteristics}

The clinical burnout sample consisted of $47 \%$ of the participants who were recruited from new enrollments of Dutch centers of expertise in burnout treatment and who received cognitive behavioral therapy conducted by a psychologist, which is considered as "psychological treatment as usual". The other 53\% was recruited through the Internet when they were about to start psychological treatment. Although the groups were recruited differently, they did not differ at baseline with respect to symptom severity, as assessed according to selection questionnaires and the diary, demographic variables, and burnout-related variables (duration of sick leave, comorbid psychopathology). At follow-up, $77 \%$ of the participants recruited through the Internet had actually received psychological treatment, $10 \%$ had only consulted their general practitioner, $10 \%$ had received alternative health care, and 3\% had refrained from treatment. The participants recruited through the Internet were somewhat less exhausted at follow-up than those recruited at the treatment centers $(F=4.30$, $\mathrm{P}=0.04)$. This was the only difference found between the two groups. At the time of the follow-up, 33\% of all of the participants had finished the treatment, 53\% had completed 1-10 sessions, and 47\% had completed 11-20 sessions. Two-thirds of the burnout participants were still involved in treatment, $24 \%$ had received 1 to 10 sessions, $51 \%$ had received $11-20$ sessions, and $24 \%$ had received more than 20 sessions. The Internet group did not differ from the group recruited through the treatment centers with respect to the number of sessions or whether the treatment was finished.

\section{Statistical analysis}

We employed multilevel regression modeling in MlwiN 2.02 (created by the Centre for Multilevel Modelling: http://www.cmm.bristol.ac.uk) to detect changes in symptom severity and to compare symptom levels between the burnout participants and the healthy controls. Multilevel regression modeling is recommended for diary data because it accounts for within-person dependencies of data points (38). This method is comparable to multiple regression analysis in that its intercept and slope parameters are analogous to unstandardized coefficients in a regular regression analysis. To examine the predictors of exhaustion and full return to work, we used 2 -week aggregates of diary variables (ie, we calculated the mean of all available records per individual). ${ }^{3}$ The predictors of exhaustion at follow-up were examined in a stepwise multiple regression analysis, and predictors of full return to work were studied in a forward stepwise logistic regression analysis. The latter analyses were conducted using SPSS 12.0 (SPSS Inc, Chicago, IL, USA).

\section{Results}

\section{Dropout analysis}

The dropout analysis showed that the participants who completed the study $(\mathrm{N}=51)$ were more highly educated $\left(\chi^{2}=7.72, \mathrm{P}<0.01\right)$ and had a shorter duration of sick leave $[\mathrm{t}(55)=2.05, \mathrm{P}=0.05]$ than those who dropped out $(\mathrm{N}=8)$. Symptom severity at baseline, as measured by the diary, did not differ between the groups $\left(\mathrm{F}_{6,49}=0.53\right.$, $\mathrm{P}=.53$ ), and no differences were found for age, gender, selection criteria (ie, MBI-GS, CIS, SCL-90), presence of comorbid major depression, source of recruitment, or partial or full-time sick leave.

\section{Symptom improvement}

Table 2 shows symptom improvement in clinical burnout after 6 months. As expected, all the symptoms had improved among those with burnout (ie, exhaustion, recovery through sleep, sleep problems, and depressed mood), but the symptom levels were still higher than those of the healthy controls.

\section{Full return to work}

Table 3 presents a cross-tabulation of return to work at baseline and follow-up. At the 6-month follow-up, $37 \%$ of the participants $(\mathrm{N}=19)$ had fully returned to work, consistent with our expectations. Six of them returned to an adapted job (4 in a different function, 1 in a different function with reduced workhours, and 1 in the same function but with reduced workhours). In a comparison with their work status at baseline, 55\% of the burnout participants had improved, either from full sick leave to partial or full return to work or from

3 Multilevel regression analysis was not appropriate in the predictive regression analyses for two reasons. First, the prediction of symptom improvement required a data file that included alarm-controlled records of exhaustion at baseline and follow-up that were at the same line. This requirement implies that the time stamps of assessments at baseline and follow-up should have been identical (eg, day 1 at 10:32 at baseline had to correspond with day 1 at 10:32 at followup). Due to the randomization of the alarm times, identical time stamps of the alarm-controlled records at baseline and follow-up were rather exceptional. Hence this method produced a data file with too many missing values, even when the precision of time equality was lessened. Second, when the dependent variable was measured at the highest level of analysis (full return to work), the independent variables had to be at the same level. 
Table 2. Symptom improvement in clinical burnout. Recovery through sleep means a difference in the fatigue level in the evening and morning diary. All other scales range from $1=$ not at all to $7=$ very. The differences were calculated from disaggregated diary data in a multilevel analysis. The test value is a Wald test that follows a normal distribution: $Z$ = estimate or standard error of the estimate. Burnout persons on partial sick leave or full sick leave at baseline did not differ with respect to symptom severity at baseline.

\begin{tabular}{|c|c|c|c|c|c|c|c|c|c|c|}
\hline \multirow[t]{3}{*}{ Symptoms } & \multicolumn{6}{|c|}{ Clinical burnout group } & \multicolumn{4}{|c|}{ Healthy reference group } \\
\hline & \multicolumn{2}{|c|}{$\begin{array}{l}\text { Base- } \\
\text { line }\end{array}$} & \multicolumn{2}{|c|}{$\begin{array}{l}\text { Six-month } \\
\text { follow-up }\end{array}$} & \multirow[t]{2}{*}{$\begin{array}{c}\text { Test } \\
\text { value }\end{array}$} & \multirow[t]{2}{*}{$\begin{array}{c}\text { P- } \\
\text { value }\end{array}$} & \multicolumn{2}{|c|}{$\begin{array}{l}\text { Base- } \\
\text { line }\end{array}$} & \multirow[t]{2}{*}{$\begin{array}{c}\text { Test } \\
\text { value }\end{array}$} & \multirow[t]{2}{*}{$\begin{array}{c}\mathrm{P}- \\
\text { value }\end{array}$} \\
\hline & Mean & SD & Mean & SD & & & Mean & SD & & \\
\hline Exhaustion & 3.34 & 0.12 & 2.56 & 0.09 & -8.58 & $<0.01$ & 1.84 & 0.17 & 4.18 & $<0.01$ \\
\hline Recovery through sleep & 1.38 & 0.14 & 1.53 & 0.09 & 2.27 & 0.02 & 2.13 & 0.27 & 2.25 & 0.02 \\
\hline Trouble falling asleep & 2.96 & 0.15 & 2.56 & 0.09 & -4.59 & $<0.01$ & 1.79 & 0.21 & 3.81 & $<0.01$ \\
\hline Refreshing sleep & 3.56 & 0.11 & 4.10 & 0.07 & 7.92 & $<0.01$ & 4.77 & 0.21 & -3.24 & $<0.01$ \\
\hline Depressed mood & 2.79 & 0.13 & 1.98 & 0.19 & -4.26 & $<0.01$ & 1.41 & 0.17 & 3.39 & $<0.01$ \\
\hline
\end{tabular}

Table 3. Return to work at the 6-month follow-up of clinical burnout.

\begin{tabular}{|c|c|c|c|c|c|c|c|c|c|c|}
\hline \multirow[t]{4}{*}{ Baseline } & \multicolumn{10}{|c|}{ Follow-up } \\
\hline & \multirow{2}{*}{\multicolumn{2}{|c|}{ Full return to work }} & \multicolumn{6}{|c|}{ No full return to work } & \multicolumn{2}{|c|}{ Total } \\
\hline & & & \multicolumn{2}{|c|}{ No job } & \multicolumn{2}{|c|}{ No return to work } & \multicolumn{2}{|c|}{ Partial return to work } & \multirow[b]{2}{*}{$\mathrm{N}$} & \multirow[b]{2}{*}{$\%$} \\
\hline & N & $\%$ & $\mathrm{~N}$ & $\%$ & N & $\%$ & N & $\%$ & & \\
\hline No return to work & 6 & 12 & 6 & 12 & 7 & 14 & 9 & 18 & 28 & 55 \\
\hline Partial return to work & 13 & 26 & 3 & 6 & 1 & 2 & 6 & 12 & 23 & 45 \\
\hline Total & 19 & 37 & 9 & 18 & 8 & 16 & 15 & 29 & 51 & 100 \\
\hline
\end{tabular}

partial return to work to full return to work. Only 10 participants $(20 \%)$ deteriorated, mainly because they lost their jobs due to reorganizations or temporary contracts. None of the jobless participants received a disability pension at follow-up.

\section{Symptom improvement and full return to work}

In addition, we examined whether full return to work cohered better with a stronger decrease in symptom severity than not full return to work did. At the follow-up, recovery through sleep, sleep problems, and depressed mood among those who fully returned to work were comparable with the levels of the healthy controls, but exhaustion was still somewhat elevated $(Z=2.12$, $\mathrm{P}=0.01)$. In contrast, those who did not fully return to work still differed from the healthy controls with respect to all symptoms (P ranging from 0.01 to 0.001 ). It appeared that, at baseline, those who later fully returned to work and those who did not were equally exhausted and depressed, but reported different levels with respect to the sleep variables. Those who fully returned to work recovered better through sleep, experienced less trouble falling asleep, and felt more refreshed in the morning $(\mathrm{P}$ ranging from 0.01 to 0.001 ). Actually, those who fully returned to work appeared to be unimpaired at baseline regarding recovery through sleep and trouble falling asleep when compared with the healthy controls (respectively, $Z=0.96, \mathrm{P}=0.34 ; Z=1.53, \mathrm{P}=0.13$ ).

\section{Sleep problems and poor recovery through sleep}

The final predictive regression models for exhaustion and full return to work at follow-up are shown in table 4. The sleep variables at baseline significantly predicted both symptom improvement and work resumption at follow-up. High exhaustion at follow-up was predicted by (in order of significance) high exhaustion at baseline, older age, shorter follow-up duration, recruitment through treatment centers (compared with the Internet), high educational level (university or college degree), and poor recovery through sleep at baseline. Full return to work was predicted by partial sick leave at baseline, more refreshing sleep, and less trouble falling asleep at baseline. Recovery through sleep and refreshing sleep were strongly correlated at baseline $(\mathrm{r}=0.63, \mathrm{P}<0.001)$, but poor recovery through sleep did not emerge as a significant predictor for full return to work when refreshing sleep was excluded from the regression model.

To account for the influence of comorbid major depression, we repeated all of the analyses and excluded 
the burnout participants with comorbid depression $(\mathrm{N}=10)$. The results did not change with respect to the first two hypotheses but did change for poor recovery through sleep and sleep problems. In other words, exhaustion severity at follow-up was no longer predicted significantly by poor recovery through sleep, although a trend remained $(\beta=-0.13, P=0.13)$, while the other predictors remained significant. Those who fully returned to work were still characterized by unaffected sleep at baseline, as has already been discussed. However, sleep problems no longer predicted full return to work in the binary logistic regression model, although a trend remained for trouble falling asleep ( score $=2.47, \mathrm{P}=0.12$ ). Instead, full return to work was predicted by being male [odds ratio (OR) 7.90, 95\% confidence interval $(95 \% \mathrm{CI})$ $1.38-45.30, \mathrm{P}<0.01]$, in addition to the influence of partial sick leave at baseline, which remained a significant predictor (OR 9.84, 95\% CI 1.71-56.6, $\mathrm{P}<0.05)$.

\section{Discussion}

The main aim of our study was to examine the possibility of recovery from clinical burnout (ie, among those on sick leave and among those who applied for treatment) within 6 months. We studied both symptom improvement and return to work, as well as their cooccurrence. In addition, we studied the influence of various aspects of sleep on burnout improvement and work resumption.

\section{Symptom improvement}

In line with our expectations, exhaustion, poor recovery through sleep, sleep problems, and depressed mood had decreased significantly within 6 months, although they were still elevated in comparison with the respective levels of a healthy reference group. As far as we know, this study is the first to examine symptom improvement with thorough and reliable assessments of symptoms at the moment of occurrence. Nevertheless, the results agreed with previous research using retrospective questionnaires $(6,11,12)$. The difference between the healthy reference group and the burnout group may have been estimated rather conservatively, since the absence of burnout complaints was used as a selection criterion for the healthy group. Given that $10 \%$ of the Dutch working population suffers from exhaustion (CBS, www.statline. $\mathrm{nl}$ ), our healthy reference group was probably more healthy than a random sample taken from the population. The current results show that significant improvement in symptoms is possible in clinical burnout within a period of 6 months.
Table 4. Prediction of exhaustion (linear regression) and full return to work (binary logistic regression) at follow-up. (SE = standard error)

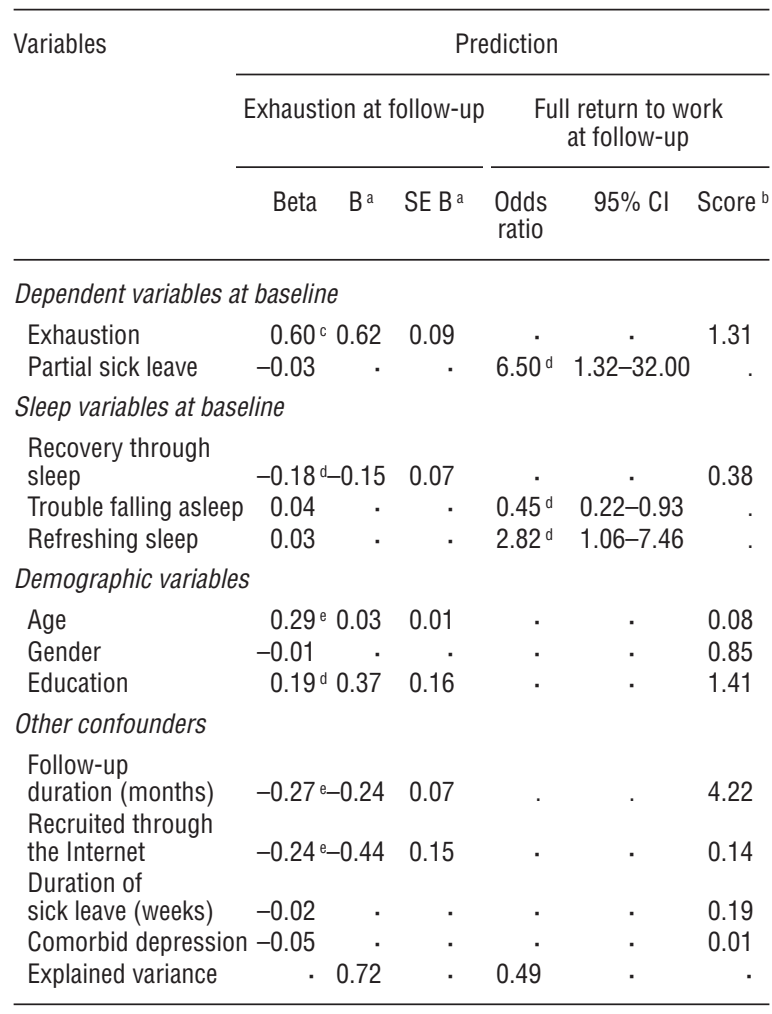

${ }^{a}$ In the stepwise regression analysis, the B coefficient and its standard error were solely given for the predictors that entered the final model.

${ }^{b}$ The score indicates the importance of a variable that did not enter the final model. The higher the score, the more important the variable.

c $P<0.001$.

d $P<0.05$.

e $P<0.01$.

\section{Full return to work}

Since "psychological treatment as usual" does not involve activation, we expected that full work resumption would be limited in clinical burnout within 6 months. Again, in line with our expectations, $37 \%$ of the clinical burnout participants had fully resumed work 6 months after their treatment onset (which equals an average of 10 months' sick leave). These results are comparable with the $39 \%$ of persons with clinical burnout who receive cognitive behavioral therapy and fully return to work within 8.5 months after treatment onset (11) and with the $50 \%$ of employees with work-related adjustment disorders who receive cognitive behavioral therapy or no treatment at all and fully return to work within 11 months after the onset of sick leave (6). Our results are in contrast to the $64 \%$ with full return to work within 3 months among employees with work-related adjustment disorders, who received care as usual by an occupational physician (12). This considerable difference is probably not due to the different clinical diagnoses used in the study of van der Klink et al (12) compared with 
ours (ie, "work-related adjustment disorders" versus "work-related neurasthenia") or to the immediate start of the intervention after sick leave in van der Klink et al's study compared with the onset of treatment at 4 months after sick leave in the our study. The results of the study by Blonk and his colleagues (6) were comparable with these aspects of the study by van der Klink et al, even though the results differed and were comparable to ours. The difference may be explained by the caregiver, since, in the study of Van der Klink et al, care was provided by an occupational health physician instead of a psychologist. It is likely that the focus of an occupational health physician is more strongly directed towards work resumption, rather than symptom improvement. We conclude that full return to work is a slow process for employees with clinical burnout who receive psychological treatment. In more than half of the cases full work resumption took more than 10 months.

Full return to work cohered with full recovery of burnout symptoms at follow-up. Those who fully returned to work appeared, however, to be already unimpaired at baseline with respect to trouble falling asleep and poor recovery through sleep. They did, however, experience full recovery from exhaustion, nonrefreshing sleep, and depression. People with partial or no work resumption of work still experienced elevated levels on all of the symptoms at follow-up. As far as we know, this is the first study to explore individual differences within the burnout group with respect to symptom improvement.

\section{Poor recovery through sleep and sleep problems}

We suggested that, when energy is not replenished on a daily basis through sleep, recovery from exhaustion (core symptom of burnout) may be hampered in the long run. This hypothesis was confirmed, as was our hypothesis that sleep problems at baseline reduced the likelihood of full work resumption within 6 months. The influence of affected sleep on return to health and on work was independent of the severity of exhaustion at baseline. However, the influence of recovery through sleep at baseline on exhaustion severity at follow-up and the influence of sleep variables on full return to work were weakened when depression was taken into account. In contrast with our findings, prior studies found that sleep problems impeded return to work in the general population, even after adjustment for psychiatric morbidity $(22,23)$. This discrepancy may be due to our small sample size. Excluding people with a comorbid depressive disorder reduced the statistical power, since weak effects for the influence of sleep variables on our outcome measures remained. For the time being, we conclude that sleep problems and poor recovery through sleep play a complicating role in symptom improvement and in return to work in clinical burnout. However, confirmation of whether this conclusion only applies to people with burnout accompanied by comorbid depression in a larger sample is still needed.

\section{Limitations}

Our study had several limitations. We did not execute a randomized controlled trial, and the treatment received was rather heterogeneous. Consequently, we do not know whether the improvement was due to treatment or occurred spontaneously. Moreover, it appeared that not all of the people who applied for treatment had received it after 6 months. However, since highly structured cognitive behavioral therapy did not influence symptom improvement in a prior study on employees with workrelated adjustment disorders, we may have observed spontaneous recovery (6). Consequently, there may not have been any differences between those who did and those who did not receive treatment. We recruited participants in two different ways (ie, via treatment centers and through the Internet). Although all of the participants intended to enroll in treatment, $25 \%$ of the Internet group had not received psychological treatment by the time of the follow-up. The participants in the treatment centers received cognitive behavioral therapy, but the psychological treatment of the Internet group may have been more heterogeneous. However, we observed almost no differences between the two groups, and the only difference found was in favor of the Internet group (less exhaustion at follow-up). Our results do not allow for conclusions concerning symptom improvement or relapse beyond 6 months. A comparable study on clinical burnout observed a stabilization of symptom levels after treatment (mean 8.5 months) (11). Since treatment had not ended for most of our participants, the symptom levels may have further decreased beyond 6 months. The possibility of generalizing our findings to the clinical burnout population may be hampered by the large proportion of highly educated persons in our sample and by the dropout of lower educated participants at follow-up. Since a high educational level was related to poorer exhaustion improvement, it can be speculated that results may be more positive for people with clinical burnout and a lower educational level. We included participants with comorbid psychiatric disorders when the onset of burnout symptoms preceded the onset of the comorbid psychiatric disorder. On the whole, the inclusion of these cases, in fact, increased the generalizability of our results since comorbid psychiatric disorders are common among patients with severe burnout (39). Comorbid depression (the most common comorbid psychopathology) did not confound most of our results, except for the influence of sleep on burnout recovery. We have already elaborated on this finding. 
Finally, our method (subjective symptom ratings) did not allow for distinguishing between sleepiness and fatigue, since people are unable to distinguish between these states clearly (36). We must therefore acknowledge that our sampling of fatigue may have included states of sleepiness.

\section{Implications}

Our most important finding is that recovery from clinical burnout can be expected, even up to approximately healthy levels, for a large group of people with burnout. This fact should be incorporated into patient education at the beginning of treatment, since the expectancy of recovery is important for recovery itself (40). Moreover, the current results indicate that assessing and treating sleep problems in clinical burnout deserves more attention. Partial work resumption at baseline was an important indicator for full work resumption at follow-up, which corresponds with the observed effect of activating interventions $(6,12)$. Therefore, work resumption in clinical burnout may be enhanced with the use of a timecontingent approach. The presence of comorbid depression does not seem to impede recovery from burnout, while high age and high educational levels do.

Further study is warranted to examine the effectiveness of psychological treatment (cognitive behavioral therapy) in clinical burnout, in comparison with spontaneous recovery, to examine the success of activating intervention and to examine the success of sleep interventions (cognitive behavioral therapy or sleep medication). Knowledge on the premorbid levels of symptoms among those with burnout would improve our understanding of our results as either full or partial recovery. The high stability of the exhaustion scores among those with mild burnout may suggest that those with clinical burnout have always functioned at "unhealthy" levels as far as exhaustion is concerned (4), but this assumption remains to be explored.

\section{Final remarks}

The bad news is that, currently, symptom improvement and return to work in clinical burnout are slow. The good news is that recovery from clinical burnout is possible within 10 months after the onset of sick leave and that much is to be gained in improving burnout treatment.

\section{References}

1. Maslach C, Schaufeli WB, Leiter MP. Job burnout. Annu Rev Psychol. 2001;52:397-422.

2. Melamed S, Shirom A, Toker S, Berliner S, Shapira I. Burnout and risk of cardiovascular disease: evidence, possible causal paths, and promising research directions. Psychol Bull. 2006;132:327-53.

3. Shirom A. Reflections on the study of burnout. Work Stress. 2005;19:263-70.

4. Taris T, Le Blanc P, Schaufeli W, Schreurs P. Are there causal relationships between the dimensions of the Maslach Burnout Inventory?: a review and two longitudinal tests. Work Stress. 2005;19:238-55.

5. Schaufeli WB, Bakker AB, Hoogduin CAL, Schaap CPDR, Kladler A. On the clinical validity of the Maslach Burnout Inventory and the Burnout Measure. Psychol Health. 2001;16:565-82.

6. Blonk R, Brenninkmeijer V, Lagerveld S, Houtman I. Return to work: a comparison of two cognitive behavioural interventions in cases of work-related psychological complaints among the self-employed. Work Stress. 2006;20:129-144.

7. van der Klink JJL, van Dijk FJH. Dutch practice guidelines for managing adjustment disorders in occupational and primary health care [discussion paper]. Scand J Work Environ Health. 2003;29(6):478-87.

8. Keijsers GPJ, Schaap CPDR, Vossen CJC, Boelaars V, van Minnen A, Hoogduin CAL. Burnout reïntegratietraining, therapeutenboek [Burnout reintegration training, therapist book]. Amsterdam: Cure \& Care Publishers; 2000.

9. Maslach C, Jackson SE. Maslach Burnout Inventory: manual. 2nd ed. Palo Alto (CA): Consulting Psychologists Press; 1986.

10. Schaufeli WB, Van Dierendonck D. Utrechtse Burnout Schaal: Handleiding [Utrecht Burnout Scale: manual]. Lisse (Netherlands): Swets Test Publishers; 2000.

11. Mommersteeg PMC, Heijnen CJ, Verbraak MJPM, van Doornen LJP. A longitudinal study on cortisol and complaint reduction in burnout. Psychoneuroendocrinology. 2006;31:793-804.

12. van der Klink JJL, Blonk RWB, Schene AH, Van Dijk FJH. Reducing long term sickness absence by an activating intervention in adjustment disorders: a cluster randomised controlled design. Occup Environ Med. 2003;60:429-37.

13. Linton SJ. Does work stress predict insomnia?: a prospective study. Br J Health Psychol. 2004;9:127-36.

14. Åkerstedt T, Fredlund P, Gillberg M, Jansson B. Work load and work hours in relation to disturbed sleep and fatigue in a large representative sample. J Psychosom Res. 2002;53:585-8.

15. Melamed S, Ugarten U, Shirom A, Kahana L, Lerman Y, Froom P. Chronic burnout, somatic arousal and elevated salivary cortisol levels. J Psychosom Res. 1999;46:591-8.

16. Söderström M, Ekstedt M, Åkerstedt T, Nilsson J, Axelsson J. Sleep and sleepiness in young individuals with high burnout scores. Sleep 2004;27:1369-77.

17. Kristensen TS, Borritz M, Villadsen E, Christensen KB. The Copenhagen Burnout Inventory: a new tool for the assessment of burnout. Work Stress. 2005;19:263-70.

18. Mommersteeg PMC, Heijnen CJ, Keijsers GPJ, Verbraak MJPM, Van Doornen LJP. Cortisol deviations in people with burnout before and after psychotherapy: a pilot study. Health Psychol. 2006;25:243-8.

19. Sonnenschein M, Sorbi MJ, Maas CJM, Van Doornen LJP, Schaufeli WB. Evidence that impaired sleep recovery may complicate burnout improvement independently of depressive mood. J Psychosom Res. 2007;62:487-94.

20. Ekstedt M, Söderström M, Åkerstedt T, Nilsson J, Søndergaard HP, Aleksander P. Disturbed sleep and fatigue in occupational burnout. Scand J Work Environ Health. 2006;32(2):121-31.

21. Shirom A, Melamed S, Toker S, Berliner S, Shapira I. Burnout 
and health review: current knowledge and future research directions. Int Rev Ind Organ Psychol. 2005;20:269-307.

22. Sivertsen B, Overland S, Neckelmann D, Glozier N, Krokstad $\mathrm{S}$, Pallesen $\mathrm{S}$, et al. The long-term effect of insomnia on work disability: the HUNT-2 historical cohort study. Am J Epidemiol. 2006;163:1018-24.

23. Eriksen W, Natvig B, Bruusgaard D. Sleep problems: a predictor of long-term work disability?: a four-year prospective study. Scand J Public Health. 2001;29:23-31.

24. Bültmann U, De Vries M, Beurskens AJHM, Bleijenberg G, Vercoulen JH, Kant I. Measurement of prolonged fatigue in the working population: determination of a cutoff point for the Checklist Individual Strength. J Occup Health Psychol. 2000;5:411-6.

25. World Health Organization (WHO). The ICD-10 classification of mental and behavioural disorders: diagnostic criteria for research. Geneva: WHO; 1993.

26. Hoogduin CAL, Knepper S, Csansky HW. Onderzoek bij psychische stoornissen voor bedrijfs- en verzekeringsartsen [Examination of psychological disorders by company and insurance doctors]. Houten [Netherlands]: Bohn Stafleu Van Loghum; 1999.

27. Arrindell WA, Ettema JHM. Symptom checklist SCL-90: handleiding bij een multidimensionele psychopathologie-indicator [Symptom checklist SCL-90: manual on a multidimensional psychopathology indicator]. Lisse (Netherlands): Swets Test Publishers; 2002.

28. Csikszentmihalyi M, Larson R. Validity and reliability of the Experience Sampling Method. J Nerv Ment Dis. 1987;175:526-36.

29. Corporation PS. Pendragon forms 3.2. Libertyville (IL): Pendragon Software Corporation; 1998

30. Houtveen JH. Diary timer. Utrecht (Netherlands): Utrecht University; 2002.

31. Sonnenschein M, Sorbi MJ, Van Doornen LJF, Maas CJ. Fea- sibility of an electronic diary in clinical burnout. Int J Behav Med. 2006;13:315-9.

32. Delespaul PAEG. Assessing schizophrenia in daily life: The Experience Sampling Method. Maastricht (Netherlands): University Press; 1995.

33. Meijman TF, Schaufeli WB. Psychische vermoeidheid en arbeid: ontwikkelingen in de A\&O-psychologie [Mental fatigue and work: developments in work and organizational psychology]. De Psycholoog. 1996;31:236-41.

34. Winwood PC, Winefield AH, Dawson D, Lushington K. Development and validation of a scale to measure workrelated fatigue and recovery: The Occupational Fatigue Exhaustion/Recovery scale (OFER). J Occup Health Psychol. 2005;47:594-606.

35. Sonnenschein M, Sorbi MJ, Doornen LJPv, Schaufeli WB, Maas CJM. Electronic diary evidence on energy depletion in clinical burnout. J Occup Health Psychol. 2007;12:402-13.

36. Shen J, Barbera J, Shapiro CM. Distinguishing sleepiness and fatigue: focus on definition and measurement. Sleep Med Rev. 2006; 10:63-76.

37. American Psychiatric Association. Diagnostic and statistical manual of mental disorders. 4th edition (DSM-IV). Washington (DC): American Psychiatric Association; 1994.

38. Schwartz JE, Stone AA. Strategies for analyzing ecological momentary assessment data. Health Psychol. 1998;17:6-16.

39. Ahola K, Honkonen T, Isometsä E, Kalimo R, Nykyri E, Aromaa A, et al. The relationship between job-related burnout and depressive disorders-results from the Finnish Health 2000 Study. J Affect Disord. 2005;88:55-62.

40. Nieuwenhuijsen K, Verbeek JH, de Boer AG, Blonk RW, van Dijk FJ. Predicting the duration of sickness absence for patients with common mental disorders in occupational health care. Scand J Work Environ Health. 2006;32(1):67-74.

Received for publication: 19 February 2007 